\title{
Knee pain after falling
}

\author{
Daniel Stephen Hendry • Robert Wissman
}

Received: 8 June 2010 /Revised: 11 October 2010 /Accepted: 14 October 2010 /Published online: 10 November 2010

(C) ISS 2010

\section{Skeletal radiology: test yourself-knee pain after falling}

\section{Part I}

A 35-year-old African American woman presents with left knee pain at the emergency room after a fall. Plain film radiography is performed Figs. 1, 2, 3 and 4.

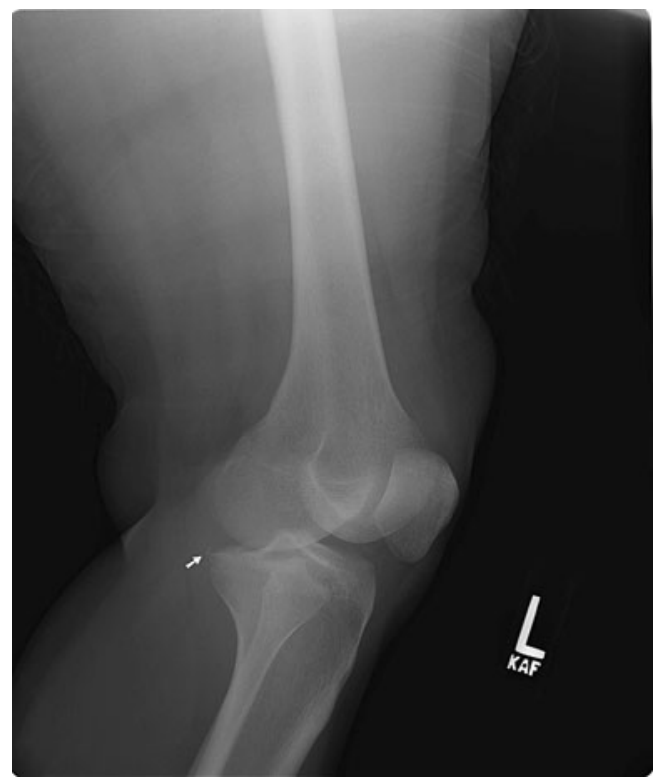

Fig. 1 Externally rotated oblique plain film radiograph of the left knee demonstrating a superiorly displaced avulsion fracture located at the posteromedial tibial plateau (arrow)

The diagnosis can be found at doi:10.1007/s00256-010-1059-1.

D. S. Hendry $(\bowtie) \cdot R$. Wissman

Department of Radiology,

University of Cincinnati College of Medicine,

234 Goodman St,

Cincinnati, OH 45267, USA

e-mail: Daniel.s.hendry@gmail.com

R. Wissman

e-mail: Robert.wissman@healthall.com

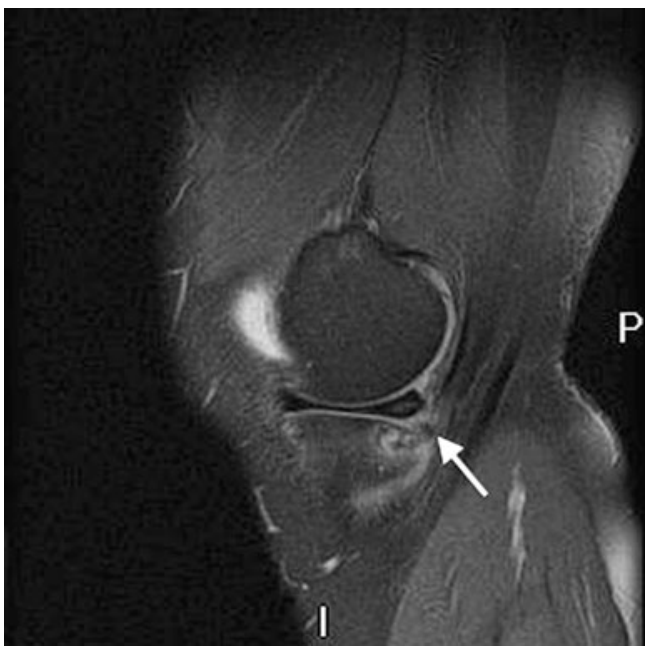

Fig. 2 Fat-suppressed T2 fast spin-echo image demonstrating the avulsion at the infraglenoid tubercle of the posteromedial tibial plateau (arrow)

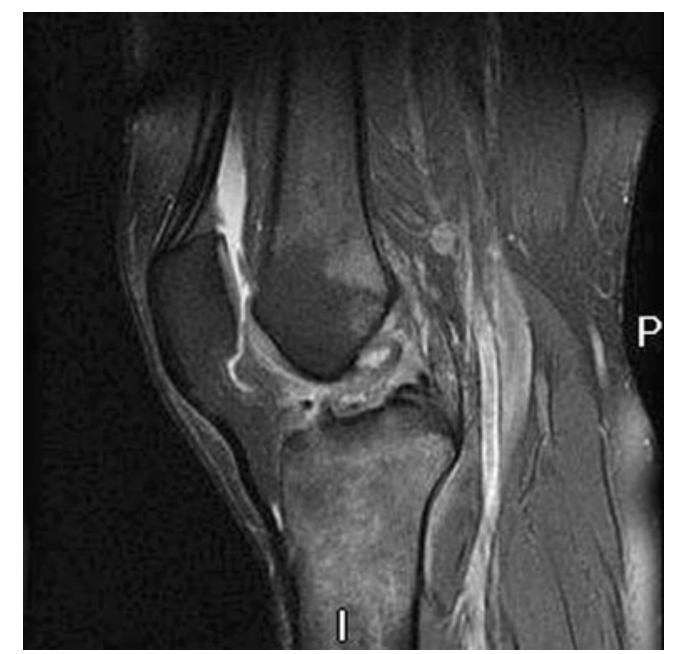

Fig. 3 Fat-suppressed T2 fast spin-echo image showing the anterior cruciate ligament 


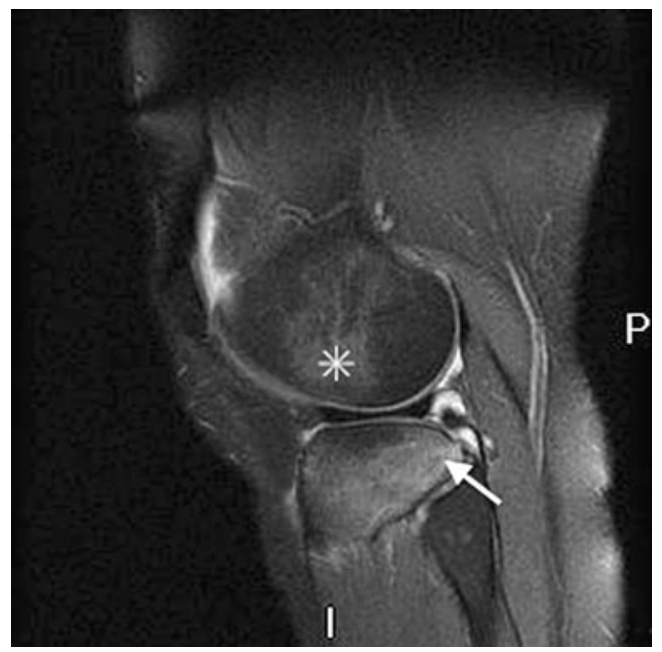

Fig. 4 Fat-suppressed T2 fast spin-echo image demonstrating contusions in the lateral femoral condyle (asterisk) and posterolateral tibial plateau (arrow)

Disclosure The authors declare that they have no conflict of interest. 